\title{
Oxidation state-dependent binding properties of the active site in a Mo-containing formate dehydrogenase
}

\author{
William E. Robinson, ${ }^{\mathrm{a}}$ Arnau Bassegoda, ${ }^{\mathrm{b}}$ Erwin Reisner ${ }^{\mathrm{a},{ }^{*}}$ and Judy Hirst ${ }^{\mathrm{b}, *}$ \\ a Department of Chemistry, University of Cambridge, Lensfield Road, Cambridge, CB2 1EW, U.K. \\ ${ }^{\mathrm{b}}$ Medical Research Council Mitochondrial Biology Unit, University of Cambridge, Wellcome \\ Trust/MRC Building, Cambridge Biomedical Campus, Hills Road, Cambridge, CB2 0XY, U.K. \\ Supporting Information Placeholder
}

\begin{abstract}
Molybdenum-containing formate dehydrogenase $\mathrm{H}$ from Escherichia coli (EcFDH-H) is a powerful model system for studies of the reversible reduction of $\mathrm{CO}_{2}$ to formate. However, the mechanism of FDH catalysis is currently debated, and whether the primary Mo coordination sphere remains saturated or one of the ligands dissociates to allow direct substrate binding during turnover is disputed. Here, we describe how oxidation state-dependent changes at the active site alter its inhibitor binding properties. Using protein film electrochemistry we show that formate oxidation by $E c F D H-H$ is inhibited strongly and competitively by $\mathrm{N}_{3}^{-}, \mathrm{OCN}^{-}, \mathrm{SCN}^{-}, \mathrm{NO}_{2}{ }^{-}$and $\mathrm{NO}_{3}{ }^{-}$, whereas $\mathrm{CO}_{2}$ reduction is inhibited only weakly and not competitively. During catalysis the Mo center cycles between the formal $\mathrm{Mo}(\mathrm{VI})=\mathrm{S}$ and $\mathrm{Mo}(\mathrm{IV})-\mathrm{SH}$ states and by modeling chronoamperometry data recorded at different potentials, substrate and inhibitor concentrations we demonstrate that both formate oxidation and $\mathrm{CO}_{2}$ reduction are inhibited by selective inhibitor binding to the $\mathrm{Mo}(\mathrm{VI})=\mathrm{S}$ state. The strong dependence of inhibitor-binding affinity on both Mo oxidation state and inhibitor electron-donor strength indicates that inhibitors (and substrates) bind directly to the Mo center. We propose that inhibitors bind to the Mo following dissociation of a selenocysteine ligand to create a vacant coordination site for catalysis, and close by considering the implications of our data for the mechanisms of formate oxidation and $\mathrm{CO}_{2}$ reduction.
\end{abstract}

\section{INTRODUCTION}

Metal-dependent formate dehydrogenase enzymes (FDHs) have recently come to prominence as efficient and reversible electrocatalysts for $\mathrm{CO}_{2}$ reduction. ${ }^{1,2}$ Both the Mo-dependent FDH from Escherichia coli $(\text { EcFDH-H })^{2}$ and the W-dependent FDH from Syntrophobacter fumaroxidans ${ }^{1}$ interconvert $\mathrm{CO}_{2}$ and formate reversibly when immobilized on graphite-based electrodes, and the Mo- 
containing FDHs from Desulfovibrio desulfuricans ${ }^{3}$ and Rhodobacter capsulatus ${ }^{4}$, along with the Wcontaining formyl-methanofuran dehydrogenase from Methanothermobacter wolfeii, ${ }^{5}$ have also been reported to reduce $\mathrm{CO}_{2}$ to formate. In contrast, no molecular electrocatalyst yet exists that is capable of reversibly interconverting $\mathrm{CO}_{2}$ and formate.

Several $\mathrm{Rh}$, Ir and $\mathrm{Ru}$ based electrocatalysts have been reported to reduce $\mathrm{CO}_{2}$ to formate. ${ }^{6-9}$ Notably, a series of Ir-pincer dihydride complexes reduce $\mathrm{CO}_{2}$ to formate with $>90 \%$ selectivity in water $^{6,7}$ and when immobilised on carbon-nanotube based electrodes. ${ }^{8}$ However, the need to develop Earth-abundant electrocatalysts is clear, and $\mathrm{Ni},{ }^{10} \mathrm{Fe}^{11,12}$ and $\mathrm{Mn}^{13}$ based electrocatalysts have also been shown to produce formate as a major product (in addition to $\mathrm{CO}$ and/or $\mathrm{H}_{2}$ ) under particular conditions. Recently, state-of-the-art electrocatalysts such as $\left[\mathrm{Fe}_{4} \mathrm{~N}(\mathrm{CO})_{12}\right]^{-14}$ and a series of CpCo-diphosphine complexes ${ }^{15}$ have been shown to reduce $\mathrm{CO}_{2}$ to formate with high activity and Faradaic efficiency in the presence of water, and proposed to catalyze via metal-hydride intermediates that $\mathrm{CO}_{2}$ may abstract or insert into. Nickel bis-diphosphine ('DuBois') catalysts oxidize formate in organic solution at up to 15.8 $\mathrm{S}^{-116,17}$ and have been proposed to operate by a $\beta$-deprotonation mechanism in which the formate proton is removed by a pendent base, not by hydride transfer to $\mathrm{Ni}^{17}$ However, all these molecular electrocatalysts require overpotentials of hundreds of $\mathrm{mV}$ in order to perform unidirectional catalysis, in stark contrast with the reversible catalysis of FDH. ${ }^{1,2}$ Thus, the FDH active site provides an attractive biological blueprint to inform the design of efficient synthetic electrocatalysts for formate oxidation and $\mathrm{CO}_{2}$ reduction. Although the principles by which enzymes such as FDH have evolved into such efficient and reversible catalysts are increasingly well understood, ${ }^{18}$ the FDH catalytic mechanism itself is currently controversial and only limited structural and functional data are available.

Several metal-dependent FDHs have been characterized structurally ${ }^{19,5,20,21}$ and show a common active-site architecture, exemplified by the structure of $E$. coli FDH-N. ${ }^{21}$ In the oxidized state the central Mo (or W) atom is coordinated to two pyranopterin (dithiolene) ligands, a terminal sulfide and a rare selenocysteine $(\mathrm{Sec})$ residue. The sulfido-ligand is crucial: sulfur-transferase enzymes are required to produce active FDH, and inactivation by cyanide, which removes the sulfido ligand, may be partially reversed by incubation with sulfide. ${ }^{22,23}$

According to a central tenet of molybdenum biochemistry, the Mo in FDH is considered to cycle between the formal $\mathrm{Mo}(\mathrm{VI}), \mathrm{Mo}(\mathrm{V})$ and $\mathrm{Mo}(\mathrm{IV})$ oxidation states during catalysis. ${ }^{24} \mathrm{We}$ use this nomenclature throughout, even though the redox non-innocent pyranopterin ligands ${ }^{25}$ may participate, particularly in the lower oxidation states. Thus, the Mo(VI) state is used to oxidize formate and the $\mathrm{Mo}(\mathrm{IV})$ state to reduce $\mathrm{CO}_{2}$. In the structures of the oxidized and formate-reduced forms of $E c \mathrm{FDH}-\mathrm{H},{ }^{19}$ 
the structure of the oxidized active site is closely similar to that of EcFDH-N but the structure of the formate-reduced active site is controversial. Initially, the site was modelled as a trigonal bipyramidal Mo center coordinated by the two pyranopterins and the Sec residue. The sulfido ligand (modelled at the time as an oxo group) was assumed to have dissociated. This structure is not consistent with the sulfido ligand being essential for function. However, the same data were subsequently reinterpreted: the loop carrying the Sec residue was modelled into a different position, with the Sec $12 \AA$ away from the Mo center, and the apical position on the Mo occupied by the sulfido ligand. ${ }^{26}$ This latter model is consistent with the structure of a catalytically-relevant state, but the existence of two such different models from the same dataset implies ambiguity in the data and suggests caution in basing further interpretations on either model. XAS data on the oxidized FDHs from E. coli and D. sulfuricans were in agreement with the Mo coordination spheres originally assigned in the X-ray crystal structures (that included a terminal oxo instead of sulfido group). ${ }^{27,28}$ XAS data on the chemically-reduced forms indicated little change to the Mo coordination sphere, except for a lengthening of the putative Mo-O bond, ${ }^{28}$ perhaps suggesting that Sec dissociation does not occur upon reduction. However, XAS data on Rhodobacter capsulatus FDH (which contains a Cys residue in place of the Sec) suggested that a Mo-S bond is replaced by a Mo-O bond upon reduction by formate. ${ }^{23}$ EPR spectroscopy has identified a characteristic Mo(V) signal upon reduction of the Mo(VI) state by formate, followed by transfer of an electron to an iron-sulfur or heme cofactor ${ }^{29-32}$. Coupling of ${ }^{77} \mathrm{Se}$ to this intermediate $\mathrm{Mo}(\mathrm{V})$ state has been observed in $E c$ FDH-H (but is not necessarily relevant to the Mo(IV) state) ${ }^{30}$ and magnetic coupling between the $\mathrm{Mo}(\mathrm{V})$ and the proton derived from the $\mathrm{C}-\mathrm{H}$ moiety of the formate has been attributed to the proton residing on the terminal sulfido ligand as a terminal thiol. ${ }^{29,32}$

On the bases of these data, several different mechanisms have been proposed for FDH-catalyzed formate oxidation, including mechanisms in which a vacant coordination site on Mo(VI) is created by Sec dissociation (Figure 1A), ${ }^{33,34}$ and mechanisms in which a saturated Mo coordination environment is maintained (Figure 1B). ${ }^{3,32}$ In the former case, various species (including the dissocated $\mathrm{Sec}^{26}$ or a nearby His residue ${ }^{19}$ ) have been proposed to act as a base to abstract a proton from formate, once it is bound to the Mo(VI) by one its carboxylate oxygens. Alternatively, formate has been suggested to displace the Sec residue from the Mo onto the terminal sulfide in a sulfur-shift reaction. ${ }^{35}$ Formate has also been proposed to donate a hydride directly to the Mo, which then migrates to the terminal sulfide in a hydride-shift reaction. ${ }^{33}$ In the latter case, direct hydride transfer of the formate $\alpha$-hydrogen to the terminal sulfido group on the Mo, without direct substrate binding to the metal, has recently been 
proposed, ${ }^{3,32}$ in analogy with the hydride-transfer mechanism proposed for the related xanthine oxidase enzymes. $^{24}$

A

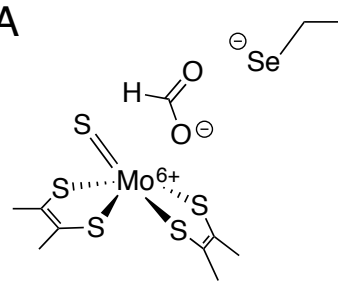

B

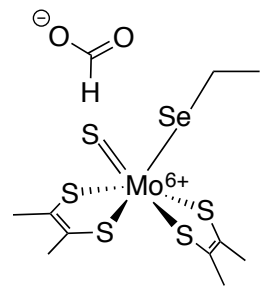

Figure 1. Formate approaches (A) a vacant primary coordination site on $\mathrm{Mo}(\mathrm{VI})$, or (B) the outer coordination sphere of a saturated $\mathrm{Mo}(\mathrm{VI})$ center in FDH. $^{3,32}$

Here, we have used protein film electrochemistry (PFE) to probe the mechanism of $\mathrm{CO}_{2}$ reduction and formate oxidation by $E c \mathrm{FDH}-\mathrm{H}$. In combination with a set of inhibitors of varying electron donor strength $\left(\mathrm{N}_{3}{ }^{-}, \mathrm{OCN}^{-}, \mathrm{SCN}^{-}, \mathrm{NO}_{2}{ }^{-}\right.$and $\left.\mathrm{NO}_{3}{ }^{-}\right)$PFE was employed to distinguish the binding characteristics of inhibitors to the reduced and oxidized active sites. We reveal that inhibitor binding is strongly oxidation state-dependent, with a strong preference for the oxidized state. Thus, inhibition of formate oxidation is strong and competitive, and inhibition of $\mathrm{CO}_{2}$ reduction weak and noncompetitive. We also show that the oxidized state has a strong electron acceptor character (inhibitor binding affinities increase with electron donor strength), consistent with direct coordination of formate to the Mo center. Finally, we discuss the implications of our results for the mechanism of FDH catalysis.

\section{EXPERIMENTAL METHODS}

$E c$ FDH-H was purified as reported previously. ${ }^{2}$ It was concentrated to $0.7-1 \mathrm{mg} \mathrm{mL}^{-1}$, aliquoted into 10 $\mu \mathrm{L}$ portions and stored at $-80{ }^{\circ} \mathrm{C}$, or short term at $-40{ }^{\circ} \mathrm{C}$ in a freezer inside in an anaerobic glovebox.

PFE was performed in a nitrogen-filled MBraun glovebox $\left(<0.1 \mathrm{ppm} \mathrm{O}_{2}\right)$ using an Ivium Compactstat potentiostat. The three-electrode cell was fitted with a Pt mesh counter electrode, an $\mathrm{Ag} / \mathrm{AgCl} /$ sat. $\mathrm{KCl}$ reference electrode (BASi) and a graphite-epoxy composite rotating disk working electrode (area $0.09 \mathrm{~cm}^{2}$, prepared as described previously ${ }^{2}$ ). The cell was thermostated at $23.5^{\circ} \mathrm{C}$ using a circulated-water jacket. Experiments were performed in $\mathrm{pH}$-corrected buffer solutions containing 25 $\mathrm{mM}$ of each of 2-(N-morpholino)ethanesulfonic acid (MES, Alfa Aesar), N-tris(hydroxymethyl)methyl3-aminopropanesulfonic acid (TAPS, Sigma Aldrich), 4-(2-hydroxyethyl)-1-piperazineethanesulfonic acid (HEPES, Sigma Aldrich) and potassium acetate (Alfa Aesar) in water from a Millipore system. For each experiment the graphite epoxy electrode was abraded with p800-grade wet and dry SiC paper (Norton), then rinsed and dried. 2.5 or $5 \mu \mathrm{L}$ of $E c F D H-H$ solution was applied to its surface and left to dry for $10 \mathrm{~min}$., before the electrode was inserted into the electrochemical cell. Stock solutions of 
substrates and inhibitors were made up in the cell buffer solution, at the same $\mathrm{pH}$ and temperature (for inhibitor titrations they also included the experimental substrate concentration). Sodium formate (Sigma Aldrich) was dried under vacuum at $100{ }^{\circ} \mathrm{C}$ and stored in a dry box. For determination of the $K_{\mathrm{M}}$ for $\mathrm{CO}_{2}$ reduction, carbonic anhydrase $\left(0.2 \mathrm{mg} \mathrm{mL}^{-1}\right)$ was added to ensure the $\mathrm{CO}_{2} /$ bicarbonate equilibrium was rapidly established. $\mathrm{CO}_{2}$ was introduced to the cell by addition of an aliquot of $\mathrm{NaHCO}_{3}($ Breckland Scientific) solution corrected to the experimental pH. Sodium azide (Fisher), sodium nitrate (Sigma Aldrich), sodium nitrite (Sigma Aldrich), sodium thiocyanate (Sigma Aldrich), sodium cyanate (Sigma Aldrich) and carbonic anhydrase (Sigma Aldrich) were purchased at the highest available purity and used as received. The $\mathrm{pH}$ of the cell solution was checked before and after each experiment; this was particularly important in validating experiments for $\mathrm{CO}_{2}$ reduction. Experiments investigating formate oxidation were preceded by holding the electrode potential at $-0.6 \mathrm{~V} v s$. SHE for several seconds before switching to the potential of the experiment. All experiments were performed with an electrode rotation rate of $2000 \mathrm{rpm}$.

When necessary, high frequency electrical noise was removed from electrochemical data by Fourier transformation and chronoamperometric data were normalized for film degradation according to a published method. ${ }^{36}$ Background currents were estimated from the processed data then tested using Dixon plots $^{37}$ of $1 /$ current vs inhibitor concentration, which are linear in the ideal case. Background currents for $K_{\mathrm{M}}$ measurements were easily determined from the current recorded in the absence of substrate. Data were fit using a program written in C (see Supplementary Information). The program calculated the normalized rate $\left(\mathrm{v} / \mathrm{v}_{0}\right)$ for each experimental condition using equations 1 and 2 (see below). Then, the square of the difference between the calculated and measured normalized rates for each data point was taken and the squared terms for all data points were summed. This summed error value was minimized by screening values for each parameter, and the minimum 'least-squares-error' (LSQE) value was taken to define the best fit. A similar procedure was applied to determine the range for each parameter. The parameter of interest was fixed, and the other parameters were varied to obtain the LSQE; the procedure was repeated for a range of values of the parameter under interrogation to gain a plot of LSQE as a function of the parameter value.

\section{RESULTS}

PFE was used to investigate the mechanism of EcFDH-H catalysis through its inhibition by a set of small molecules, $\mathrm{N}_{3}^{-}, \mathrm{OCN}^{-}, \mathrm{SCN}^{-}, \mathrm{NO}_{2}^{-}, \mathrm{NO}_{3}{ }^{-}, \mathrm{CS}_{2}$ and $\mathrm{CO}$. Inhibition by $\mathrm{N}_{3}^{-}, \mathrm{NO}_{2}^{-}$and $\mathrm{NO}_{3}{ }^{-}$has been reported previously. ${ }^{38-40}$ Figure 2 shows data from a typical experiment reporting on the inhibition 
of catalysis by a protein film of $E c F D H-H$ adsorbed on a graphite-epoxy rotating disk electrode. Figure 2A shows a chronoamperometry trace (corrected for film degradation) ${ }^{36}$ which monitored the formate oxidation current while aliquots of $\mathrm{NaN}_{3}$ solution were added. The formate oxidation current is proportional to the rate of turnover. ${ }^{41}$ Figure $2 \mathrm{~B}$ displays the normalized current values $\left(\mathrm{v} / \mathrm{v}_{0}\right.$, the current observed at the given inhibitor concentration divided by the current observed in the absence of inhibitor) plotted against $\mathrm{NaN}_{3}$ concentration and fit using the standard dose-effect relationship to determine the $\mathrm{IC}_{50}$ value (the inhibitor concentration that decreases the activity by $50 \%$ ). For each inhibitor studied, three sets of data at different substrate concentrations were acquired for both formate oxidation and $\mathrm{CO}_{2}$ reduction. Note that we use the term ' $\mathrm{CO}_{2}$ concentration' to denote the total concentration of $\mathrm{CO}_{2} /$ carbonate species present in solution.

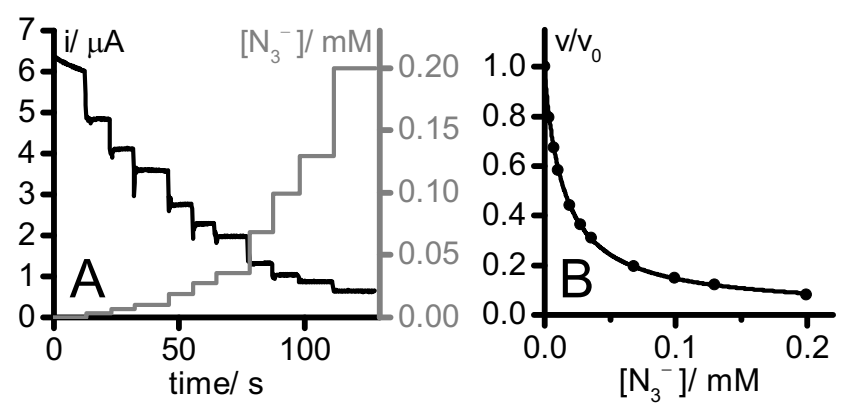

Figure 2. (A) Chronoamperometry trace recorded at $-0.1 \mathrm{~V}$ vs. SHE in $5 \mathrm{mM}$ aqueous sodium formate solution $\left(\mathrm{pH} 7,23.5^{\circ} \mathrm{C}\right.$, electrode rotation rate $2000 \mathrm{rpm})$. Aliquots of a $15 \mathrm{mM}$ solution of $\mathrm{NaN}_{3}$ (also containing $5 \mathrm{mM}$ formate) were added to adjust the $\mathrm{N}_{3}{ }^{-}$concentration (right axis). $\mathrm{pH}$ and substrate concentration were constant throughout and the data have been corrected for film loss. ${ }^{36}$ (B) Dependence of the normalized current $\left(\mathrm{v} / \mathrm{v}_{0}\right.$, the current observed at the given inhibitor concentration divided by the current observed in the absence of inhibitor) on $\mathrm{NaN}_{3}$ concentration, derived from the data in (A). The data have been fit using the standard dose-effect relationship $\left(\mathrm{v} / \mathrm{v}_{0}=\right.$ $1-\left(\left[\mathrm{N}_{3}^{-}\right] /\left(\mathrm{IC}_{50}+\left[\mathrm{N}_{3}^{-}\right]\right)\right)$with a Hill coefficient of 1 .

Figure 3 shows the $\mathrm{IC}_{50}$ values determined for inhibition by $\mathrm{N}_{3}^{-}, \mathrm{OCN}^{-}, \mathrm{SCN}^{-}, \mathrm{NO}_{2}^{-}$and $\mathrm{NO}_{3}^{-}$. No significant inhibition was observed for $\mathrm{CS}_{2}$ (up to $0.3 \mathrm{mM}$ ) or $\mathrm{CO}$ (up to $1.31 \mathrm{mM}$ ). All five inhibitors are considerably more potent against formate oxidation than $\mathrm{CO}_{2}$ reduction. Furthermore, the $\mathrm{IC}_{50}$ values for formate oxidation increase with increasing substrate concentration, whereas for $\mathrm{CO}_{2}$ reduction they decrease (or are little affected). Notably, the positive, linear relationship between the $\mathrm{IC}_{50}$ value and substrate concentration exhibited by the formate oxidation data is a clear indication for competitive inhibition, suggesting that the inhibitors bind to the Mo(VI) state. ${ }^{42}$ Conversely, the data in Figure 3 provide no indication that $\mathrm{CO}_{2}$ reduction is inhibited competitively, and the much weaker inhibition of $\mathrm{CO}_{2}$ reduction reflects a significant difference in the binding character of the oxidized and 
reduced active sites. The different binding character must reflect the different oxidation state of the Mo center itself, which is considered to convert between the deprotonated Mo(VI)-sulfido center $(\mathrm{Mo}(\mathrm{VI})=\mathrm{S})$ and the protonated $\mathrm{Mo}(\mathrm{IV})$ thiol center $(\mathrm{Mo}(\mathrm{IV})-\mathrm{SH}$, inferred from the assignment of $\mathrm{Mo}(\mathrm{V})-\mathrm{SH}$ in EPR spectra). ${ }^{32}$
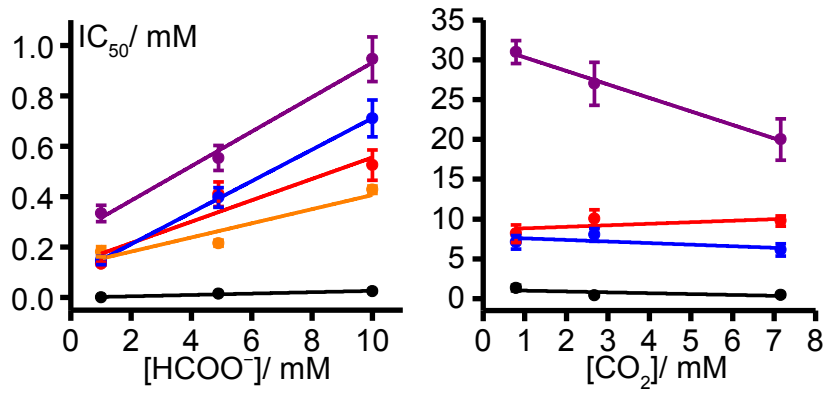

Figure 3. Dependence of inhibitor $\mathrm{IC}_{50}$ values on substrate concentration for formate oxidation and $\mathrm{CO}_{2}$ reduction. $\mathrm{NO}_{2}^{-}$is reduced by the electrode so was omitted from the $\mathrm{CO}_{2}$ reduction graph. Black: $\mathrm{N}_{3}{ }^{-}$, red: $\mathrm{OCN}^{-}$, blue: $\mathrm{SCN}^{-}$, purple: $\mathrm{NO}_{3}{ }^{-}$, orange: $\mathrm{NO}_{2}^{-}$. Conditions: $23.5^{\circ} \mathrm{C}, \mathrm{pH} 7,-0.1 \mathrm{~V}$ vs. SHE (formate), $-0.6 \mathrm{~V} v s . \mathrm{SHE}\left(\mathrm{CO}_{2}\right)$.

Previously, $\mathrm{N}_{3}^{-}$was reported to inhibit formate oxidation by $E c F D H-H$ in a 'noncompetitive' manner, and it was proposed to bind, when formate is bound, with a $K_{\mathrm{I}}$ of 75 or $88 \mu \mathrm{M} .^{38}$ In a different study on $D$. desulfuricans FDH it was reported to inhibit formate oxidation competitively with a $K_{\mathrm{I}}$ of $33 \mu \mathrm{M}$, as well as 'uncompetitively' with a $K_{\mathrm{I}}$ of $214 \mu \mathrm{M} .^{31}$ The oxidation state dependence of inhibitor binding was not considered and the mode of $\mathrm{N}_{3}{ }^{-}$inhibition thus remained unclear. $\mathrm{NO}_{3}{ }^{-}$was reported to inhibit formate oxidation by $E c$ FDH-H competitively with a $K_{\mathrm{I}}$ of $7.1 \mathrm{mM}{ }^{38}$ and $R$. capsulatus FDH with a $K_{\mathrm{I}}$ of $1.6 \mathrm{mM}^{39} \mathrm{NO}_{2}^{-}$was also proposed to be coordinated to the Mo center in an X-ray crystal structure of $E c \mathrm{FDH}-\mathrm{H} .{ }^{19}$ Importantly, using these published $K_{\mathrm{I}}$ values to predict $\mathrm{IC}_{50}$ values (using a competive inhibition model and the published $K_{\mathrm{M}}$ of $26 \mathrm{mM}^{42}$ ) led to much higher values than reported in Figure 3, leading us to undertake a detailed consideration of how the inhibition may be rationalized mechanistically.

To investigate the characteristics of inhibition in greater depth we focused on $\mathrm{N}_{3}{ }^{-}$, the strongest inhibitor, and investigated data from a comprehensive set of titrations of both formate oxidation and $\mathrm{CO}_{2}$ reduction at different substrate concentrations and potentials (see Figure 4). The data can be explained qualitatively by considering the steady-state population of the $\mathrm{Mo}(\mathrm{VI})$ state, to which $\mathrm{N}_{3}{ }^{-}$ binds preferentially, and which is governed by a balance between substrate binding/turnover (enzyme catalysis) and interfacial electron transfer to/from the electrode. First, the $\mathrm{IC}_{50}$ values determined are strongly potential dependent. For inhibition of $\mathrm{CO}_{2}$ reduction they decrease from $800 \mu \mathrm{M}$ at $-0.6 \mathrm{~V} v s$. SHE to $10.3 \mu \mathrm{M}$ at $-0.4 \mathrm{~V}$ vs. SHE (in $8.3 \mathrm{mM} \mathrm{CO}_{2}$ ) and for inhibition of formate oxidation from 61 
$\mu \mathrm{M}$ at $-0.4 \mathrm{~V} v s$. SHE to $25 \mu \mathrm{M}$ at $-0.1 \mathrm{~V} v$ s. SHE (in $10 \mathrm{mM}$ formate). The explanation is that at negative potentials the steady-state level of the $\mathrm{Mo}(\mathrm{VI})$ state is low, resulting in poor inhibition by $\mathrm{N}_{3}^{-}$, whereas at less negative potentials the level increases, and inhibition increases. Catalysis is most sensitive to potential around the FDH active site potentials (see below), which overlap more closely with the region of $\mathrm{CO}_{2}$ reduction. Second, the $\mathrm{IC}_{50}$ values determined are also strongly substrate concentration dependent. Their values increase to $1.3 \mathrm{mM}$ in the lower $\mathrm{CO}_{2}$ concentration of $0.8 \mathrm{mM}$ (at $-0.6 \mathrm{~V}$ vs. SHE) and decrease to $0.7 \mu \mathrm{M}$ in the lower formate concentration of $1 \mathrm{mM}$ (at $-0.1 \mathrm{~V} v s$. $\mathrm{SHE}$ ). Decreasing the $\mathrm{CO}_{2}$ concentration decreases the rate of $\mathrm{CO}_{2}$ reduction and thus the level of the $\mathrm{Mo}(\mathrm{VI})$ state, resulting in weaker inhibition by $\mathrm{N}_{3}{ }^{-}$. Conversely, decreasing the formate concentration increases the level of the Mo(VI) state (also formate competes less with the $\mathrm{N}_{3}{ }$ ) so inhibition increases. Thus, the potential- and substrate-dependent inhibition observed is consistent with the Mo(VI) state as the target for $\mathrm{N}_{3}^{-}$binding.

Our $\mathrm{N}_{3}^{-}$inhibition data were used quantitatively to evaluate the mechanism shown in Scheme 1, which represents the two directions of catalysis as EECC reactions. Two (reversible) interfacial electron transfer steps generate the active oxidation state of the Mo center, followed by formate oxidation or $\mathrm{CO}_{2}$ reduction by a (two-step) Michaelis-Menten mechanism. Scheme 1 assumes that substrate mass transport to the electrode surface is fast and not rate limiting (increasing the electrode rotation rate did not lead to any significant increase in catalytic current). Similarly, product diffusion away from the surface was assumed to be fast; based on a product concentration of zero in the enzyme vicinity, product dissociation was then assumed to be irreversible. Intramolecular electron transfer between the Mo center and the single $[4 \mathrm{Fe}-4 \mathrm{~S}]$ cluster was not considered, such that interfacial electron transfer was assumed to occur directly between the Mo center and the electrode. ${ }^{43}$ Finally, the inhibitor-bound species were considered to be redox inactive in the potential range investigated.

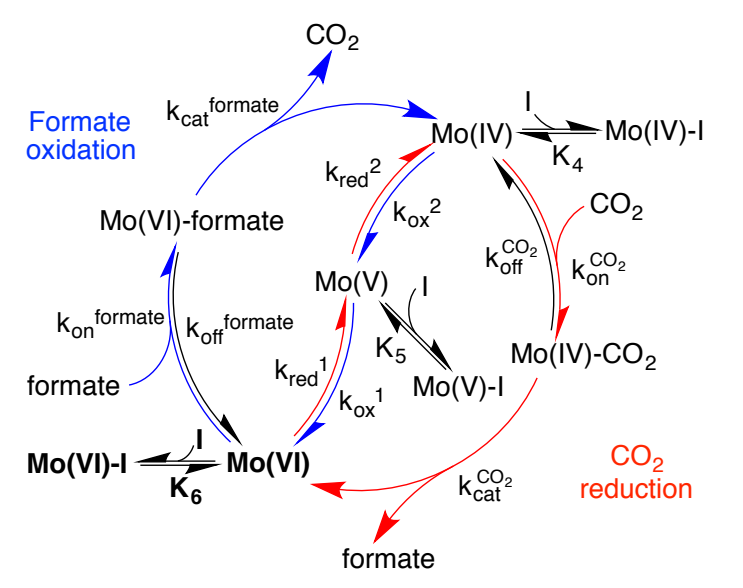

Scheme 1. Model for inhibition of $E c F D H-H$ electrocatalysis. Mo(VI), Mo(V) and Mo(IV) refer to the active site in different Mo oxidation states. 
We used Scheme 1 to derive steady-state equations for both formate oxidation and $\mathrm{CO}_{2}$ reduction (see Supplemenatry Information). Equations 1 and 2 contain seven independently-adjustable parameters, of which five are common to both reactions. $\left(k_{\mathrm{red}}{ }^{1} / k_{\mathrm{ox}}{ }^{1}\right)$ and $\left(k_{\mathrm{red}}{ }^{2} / k_{\mathrm{ox}}{ }^{2}\right)$ are functions of the active site potentials $E_{1}$ and $E_{2}$, respectively, and relate the catalytic activity to the electrode potential. The inhibitor dissociation constants, $K_{6}, K_{5}$ and $K_{4}$, refer to $\mathrm{Mo}(\mathrm{VI}), \mathrm{Mo}(\mathrm{V})$ and $\mathrm{Mo}(\mathrm{IV})$, respectively. The maximum enzyme turnover rates in each direction appear in eq. 1 and 2 relative to $k_{0}$, the interfacial electron transfer exchange constant, as $\left(k_{\mathrm{cat}}{ }^{\mathrm{CO} 2} / k_{0}\right)$ and $\left(k_{\mathrm{cat}}\right.$ formate $\left./ k_{0}\right)$. Finally, two further parameters, the Michaelis-Menten constants $K_{\mathrm{M}}{ }^{\mathrm{CO} 2}$ and $K_{\mathrm{M}}{ }^{\text {formate }}$ (where $K_{\mathrm{M}}=\left(k_{\mathrm{on}}+k_{\mathrm{cat}}\right) / k_{\text {off }}$ ) are used in the usual sense to describe formation of the enzyme-substrate complexes for each reaction. They were estimated in separate experiments that monitored the current as a function of substrate concentration (see Supplementary Figure $\mathrm{S} 1$ ) to be $K_{\mathrm{M}}{ }^{\mathrm{CO} 2}=2.5 \mathrm{mM}$ and $K_{\mathrm{M}}{ }^{\text {formate }}=0.8 \mathrm{mM}$, and their values fixed accordingly.

Equation 1 (inhibition of $\mathrm{CO}_{2}$ reduction by $E c \mathrm{FDH}-\mathrm{H}$ ):

$$
\frac{v}{v_{0}}=\frac{\frac{K_{M}^{C O_{2}}}{\left[\mathrm{CO}_{2}\right]}\left[\varepsilon_{2}\left(\varepsilon_{1}+1\right)+1\right]+\left[\frac{k_{c a t}^{C O 2}}{k_{0}} \sqrt{\varepsilon_{2}}\left(\varepsilon_{1}+\varepsilon_{3}+1\right)+1\right]}{\frac{K_{M}^{C O}}{\left[\mathrm{CO}_{2}\right]}\left[\varepsilon_{2}\left(\varepsilon_{1}\left(1+\frac{[\mathrm{I}]}{\mathrm{K}_{6}}\right)+\frac{[\mathrm{I}]}{\mathrm{K}_{5}}+1\right)+\frac{[\mathrm{I}]}{\mathrm{K}_{4}}+1\right]+\left[\frac{k_{\text {cat }}^{C O 2}}{k_{0}} \sqrt{\varepsilon_{2}}\left(\left(\varepsilon_{1}+\varepsilon_{3}\right)\left(1+\frac{[\mathrm{I}]}{\mathrm{K}_{6}}\right)+\frac{[\mathrm{I}]}{\mathrm{K}_{5}}+1\right)+1\right]}
$$

Equation 2 (inhibition of formate oxidation by $E c \mathrm{FDH}-\mathrm{H}$ ):

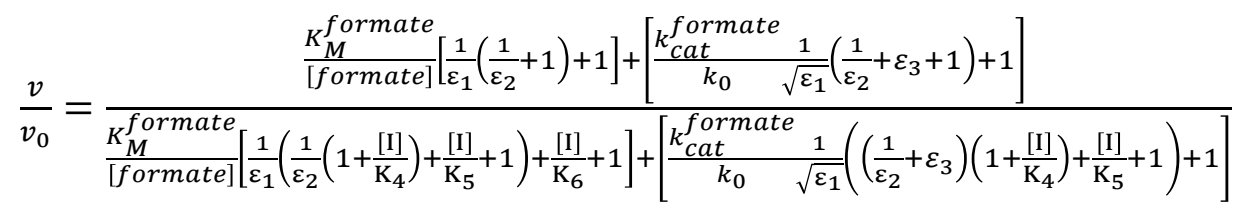

Equation 3 (the high overpotential limit of equation S2):

$$
\frac{v}{v_{0}}=\frac{\frac{K_{M}^{\text {formate }}}{[\text { formate }]}+1}{\frac{K_{M}^{\text {formate }}}{[\text { formate }]}\left[\frac{[\mathrm{I}]}{\mathrm{K}_{6}}+1\right]+1}
$$

where $\mathrm{v}$ is the calculated rate of catalysis, $\mathrm{v}_{0}$ is the calculated rate when the inhibitor concentration is zero, $n$ is the number of electrons involved in each redox couple (equal to 1 ), $F$ is Faraday's constant, $R$ is the ideal gas constant, $T$ is temperature $(297 \mathrm{~K}), E$ is the electrode potential (V vs. SHE), $k_{0}$ is the interfacial electron transfer exchange constant, $E_{1}$ is the reduction potential of the $\mathrm{Mo}(\mathrm{VI} / \mathrm{V})$ couple, $E_{2}$ is the reduction potential of the Mo(V/IV) couple and: 


$$
\begin{aligned}
& \varepsilon_{1}=\frac{\mathrm{k}_{\text {ox }}^{1}}{\mathrm{k}_{\text {red }}^{1}}=\frac{k_{0} \exp \left[\frac{F}{2 R T}\left(E-E_{1}\right)\right]}{k_{0} \exp \left[-\frac{F}{2 R T}\left(E-E_{1}\right)\right]}=\exp \left[\frac{n F}{R T}\left(E-E_{1}\right)\right] \\
& \varepsilon_{2}=\frac{\mathrm{k}_{\text {ox }}^{2}}{\mathrm{k}_{\text {red }}^{2}}=\frac{k_{0} \exp \left[\frac{F}{2 R T}\left(E-E_{2}\right)\right]}{k_{0} \exp \left[-\frac{F}{2 R T}\left(E-E_{2}\right)\right]}=\exp \left[\frac{n F}{R T}\left(E-E_{2}\right)\right] \\
& \varepsilon_{3}=\frac{k_{\text {red }}^{2}}{k_{\text {red }}^{1}}=\frac{k_{o x}^{1}}{k_{o x}^{2}}=\frac{k_{0} \exp \left[-\frac{F}{2 R T}\left(E-E_{2}\right)\right]}{k_{0} \exp \left[-\frac{F}{2 R T}\left(E-E_{1}\right)\right]}=\exp \left(\frac{F}{R T}\left(E_{\text {red }}^{2}-E_{\text {red }}^{1}\right)\right)
\end{aligned}
$$

The best-fit to the data (see Figure 4) was identified by studying different parameter combinations and minimizing the sum of the squared differences between the data points and their matching calculated rates (the least-squares error value, LSQE). Then, the range for each parameter, within which acceptable fits can be generated, was estimated by fixing the investigated parameter and varying the others to minimize the LSQE. The LSQE values obtained were plotted against the investigated parameter and the acceptable LSQE threshold determined by inspection (see Supplementary Figure S2).
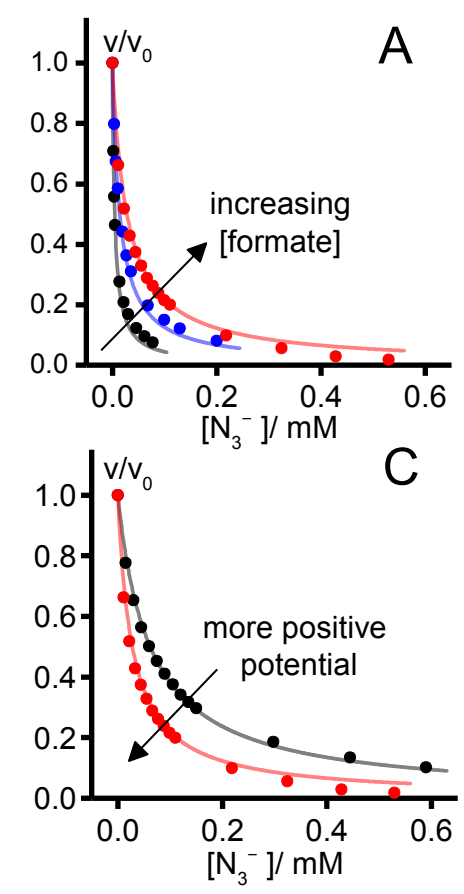
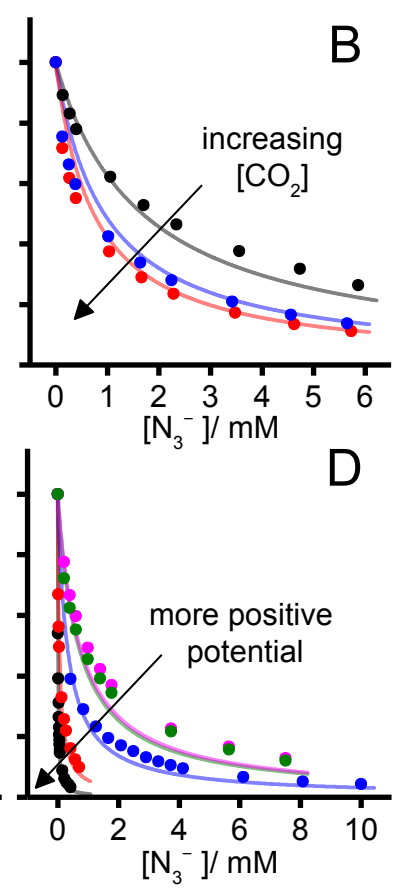

Figure 4. Global fits to data on the inhibition of formate oxidation and $\mathrm{CO}_{2}$ reduction by $\mathrm{N}_{3}^{-}$, using equations S1 and S2 with common parameters. (A): Dependence of normalized formate oxidation rate on $\mathrm{N}_{3}{ }^{-}$concentration for three formate concentrations (red: $10 \mathrm{mM}$, blue: $5 \mathrm{mM}$, black: 1 $\mathrm{mM}$ ), at $-0.1 \mathrm{~V}$ vs. SHE. (B): Dependence of normalized $\mathrm{CO}_{2}$ reduction rate on $\mathrm{N}_{3}{ }^{-}$concentration for three $\mathrm{CO}_{2}$ concentrations (red: $7.16 \mathrm{mM}$, blue, $2.67 \mathrm{mM}$, black: $0.79 \mathrm{mM}$ ) at $-0.6 \mathrm{~V} v \mathrm{~s}$. SHE. (C): Dependence of normalized formate oxidation rate on $\mathrm{N}_{3}{ }^{-}$concentration for two potentials (red: $-0.1 \mathrm{~V}$ vs. SHE, black: $-0.4 \mathrm{~V}$ vs. SHE) in $10 \mathrm{mM}$ formate. (D): Dependence of normalized $\mathrm{CO}_{2}$ reduction rate on $\mathrm{N}_{3}{ }^{-}$concentration for five potentials (pink: $-0.6 \mathrm{~V}$, green: -0.55 , blue: -0.5 , red: -0.45 , black: $-0.4 \mathrm{~V} v \mathrm{~s}$. SHE) in $8.31 \mathrm{mM} \mathrm{CO}_{2}$. Best fit lines were calculated using: $K_{\mathrm{M}}{ }^{\mathrm{CO} 2}=2.5 \mathrm{mM}, K_{\mathrm{M}}{ }^{\text {formate }}=0.8 \mathrm{mM}, K_{6}=2 \mu \mathrm{M}, K_{5}=1 \mathrm{M}, K_{4}=42 \mathrm{mM}, E_{1}$ $=-0.365 \mathrm{~V}, E_{2}=-0.656 \mathrm{~V} \cdot k_{\mathrm{cat}}^{\mathrm{CO} 2} / k_{0}=5.13, k_{\mathrm{cat}}{ }^{\text {formate }} / k_{0}=0.5$. Conditions: $\mathrm{pH} 7,23.5^{\circ} \mathrm{C}$. 
Figure 4 confirms that $\mathrm{N}_{3}{ }^{-}$binds more strongly to the $\mathrm{Mo}(\mathrm{VI})$ state than to the $\mathrm{Mo}(\mathrm{V})$ or $\mathrm{Mo}(\mathrm{IV})$ states. The best-fit value for $K_{6}$ is $2 \mu \mathrm{M}$, and it has a tightly constrained range of $1.1-3.4 \mu \mathrm{M}$. This is much smaller than previously published values $(75,88 \text { or } 33 \mu \mathrm{M})^{31,38}$ that were determined in steadystate analyses using a $K_{\mathrm{M}}{ }^{\text {formate }}$ value of $26 \mathrm{mM}$ and substrate concentrations in the range 9-120 $\mathrm{mM}$ (well above the $K_{\mathrm{M}}^{\text {formate }}=0.8 \mathrm{mM}$ value determined here). At these high concentrations the $\mathrm{IC}_{50}$ value does not respond strongly to the substrate concentration, confounding the $K_{\mathrm{I}}$ measurements. Furthermore, the steady-state analyses used benzyl viologen as the electron acceptor. ${ }^{38}$ Benzyl viologen is a non-physiological electron acceptor that is much less efficient at regenerating the Mo(VI) state than the electrode used here. Therefore, the Mo(VI) state is present at decreased levels, and even higher inhibitor concentrations are needed to affect the rate. This comparison underlines the advantage of using PFE to observe the potential-dependent characteristics of catalysis. For $K_{4}$ and $K_{5}$ the best-fit values determined are much higher than for $K_{6}$ (formally $42 \mathrm{mM}$ and $1 \mathrm{M}$ ), and the data can be fit with wide ranges of both parameters $(>17 \mu \mathrm{M}$ and $>1.1 \mathrm{mM}$, respectively, up to $1 \mathrm{M})$ showing that inhibitor binding to $\mathrm{Mo}(\mathrm{V})$ and $\mathrm{Mo}(\mathrm{IV})$ exerts little influence. Further support for inhibition of both directions of catalysis being dominated by inhibitor binding to the Mo(VI) state was provided by applying equation 3, the high-overpotential limit of equation 2 , to the data in Figure 4A. To form equation $3, k_{\mathrm{ox}}{ }^{1}$ and $k_{\mathrm{ox}}{ }^{2}$ were tended to infinity, such that the populations of $\mathrm{Mo}(\mathrm{V})$ and $\mathrm{Mo}(\mathrm{IV})$ approach zero and active site regeneration is instantaneous. Thus, equation 3 describes purely competitive inhibition of formate oxidation via $K_{6}$. Equation 3 fitted the data in Figure 4A to the same standard as equation 2 and gave a best-fit value of $K_{6} \sim 2 \mu \mathrm{M}$, supporting both the central role of $\mathrm{Mo}(\mathrm{VI})$ in formate oxidation, and competition between $\mathrm{N}_{3}{ }^{-}$and formate for the $\mathrm{Mo}(\mathrm{VI})$ state.

Data on the other inhibitors studied (see Supplementary Figure S3) indicate a similar preference for $\mathrm{Mo}(\mathrm{VI})$. $\mathrm{OCN}^{-}, \mathrm{SCN}^{-}$and $\mathrm{NO}_{3}{ }^{-}$all compete with formate for the $\mathrm{Mo}(\mathrm{VI})$ state (see Figure 3). The smaller datasets acquired for these inhibitors were fit using the best-fit values for the inhibitorindependent parameters $E_{1}, E_{2}, k_{\text {cat }}^{\text {formate }} / k_{0}$ and $k_{\text {cat }}{ }^{\mathrm{CO} 2} / k_{0}$ from Figure 4 . The values and ranges obtained for $K_{6}, K_{5}$ and $K_{4}$ were derived as shown in Figure S4 and are given in Table 1. The best-fit values for $K_{6}$ range from $51 \mu \mathrm{M}$ for $\mathrm{OCN}^{-}$to $95 \mu \mathrm{M}$ for $\mathrm{NO}_{2}{ }^{-}$, consistent with them being weaker inhibitors than $\mathrm{N}_{3}{ }^{-}$. For $\mathrm{OCN}^{-}, \mathrm{SCN}^{-}$and $\mathrm{NO}_{3}{ }^{-}, K_{5}$ and $K_{4}$ were (as for $\mathrm{N}_{3}{ }^{-}$) substantially larger than $K_{6}$. Only $\mathrm{NO}_{2}{ }^{-}$ lacked clear selectivity for the Mo(VI) state, instead showing a reverse trend with $K_{4}<K_{5}<K_{6}$. This may be because the bent $\mathrm{NO}_{2}{ }^{-}$molecule (which is isoelectronic with $\mathrm{CO}_{2}{ }^{2-}$ ) mimics an intermediate state between $\mathrm{CO}_{2}$ and formate. 
To further explore the factors that influence inhibitor binding to the active site we investigated the $\mathrm{pH}$-dependence of the inhibition of formate oxidation by $\mathrm{N}_{3}{ }^{-}$. Experiments were performed at +0.4 $\mathrm{V}$ overpotential, relative to the ( $\mathrm{pH}$-dependent) Nernst potential of the $\mathrm{CO}_{2} /$ formate couple, to access the high-potential limit where equation 3 can be applied. First, $K_{\mathrm{M}}{ }^{\text {formate }}$ was measured and found to increase from $0.18 \mathrm{mM}$ at $\mathrm{pH} 5.33$ to $\sim 1.05 \mathrm{mM}$ at $\mathrm{pH} 8$ (Figure 5A); its values were then used in equation 3 to determine $K_{6}{ }^{\text {azide }}$ as a function of $\mathrm{pH}$ (Figure 5B). $K_{6}{ }^{\text {azide }}$ increased from $0.26 \mu \mathrm{M}$ at $\mathrm{pH} 5.33$ to $3 \mu \mathrm{M}$ at $\mathrm{pH}$ 9. Figures 5A and 5B both indicate that both formate and azide bind most strongly to the oxidized state at low $\mathrm{pH}$. The data for $K_{6}{ }^{\text {azide }}$ were fitted to the thermodynamic scheme shown in Figure 5C, which describes $\mathrm{pH}$-dependent binding coupled to the ionization of a single group/residue with estimated $\mathrm{p} K_{\mathrm{a}}$ values of 6.5 in the absence of the inhibitor and 7.3 in its presence. These $\mathrm{p} K$ values are most consistent with the protonation state of a His, or $\mathrm{Cys} / \mathrm{Sec}$ residue as one of the determinants of substrate/inhibitor binding affinity.

\begin{tabular}{|c|c|c|c|c|c|}
\hline Inhibitor & $\mathbf{E}_{\mathbf{L}} / \mathbf{V} \mathbf{v s} \mathbf{N H E}^{44}$ & $\mathbf{R}^{45}$ & $K_{6}$ & $K_{5}$ & $K_{4}$ \\
\hline $\mathbf{N}_{3}^{-}$ & -0.3 & -0.4 & $\begin{array}{c}2 \mu \mathrm{M} \\
(1.1-3.4 \mu \mathrm{M})\end{array}$ & $\begin{array}{c}1 \mathrm{M} \\
(>1.1 \mathrm{mM})\end{array}$ & $\begin{array}{c}41.7 \mathrm{mM} \\
(>17 \mu \mathrm{M})\end{array}$ \\
\hline $\mathbf{O C N}^{-}$ & -0.25 & -0.12 & $\begin{array}{c}51 \mu \mathrm{M} \\
(39-65 \mu \mathrm{M})\end{array}$ & $\begin{array}{c}25 \mathrm{mM} \\
(>14 \mathrm{mM})\end{array}$ & $\begin{array}{c}1.2 \mathrm{mM} \\
(>0.53 \mathrm{mM})\end{array}$ \\
\hline $\mathbf{S C N}^{-}$ & -0.06 & -0.13 & $\begin{array}{c}56 \mu \mathrm{M} \\
(43-72 \mu \mathrm{M})\end{array}$ & $\begin{array}{c}9.7 \mathrm{mM} \\
(>6.6 \mathrm{mM})\end{array}$ & $\begin{array}{c}3.5 \mathrm{mM} \\
(>0.65 \mathrm{mM})\end{array}$ \\
\hline $\mathrm{NO}_{2}^{-}$ & 0.02 & 0.13 & $\begin{array}{c}95 \mu \mathrm{M} \\
(58-184 \mu \mathrm{M})\end{array}$ & $\begin{array}{c}1.85 \mu \mathrm{M} \\
(0.72-2.33)\end{array}$ & $\begin{array}{c}0.01 \mu \mathrm{M} \\
(>2.4 \mathrm{nM})\end{array}$ \\
\hline $\mathrm{NO}_{3}{ }^{-}$ & -1.3 & 0.22 & $\begin{array}{c}90 \mu \mathrm{M} \\
(66-122 \mu \mathrm{M})\end{array}$ & $\begin{array}{c}63 \mathrm{mM} \\
(>29 \mathrm{mM})\end{array}$ & $\begin{array}{l}16.1 \mathrm{mM} \\
(>2 \mathrm{mM})\end{array}$ \\
\hline
\end{tabular}

Table 1. Best fit values and ranges of $K_{6}, K_{5}$ and $K_{4}$ for each inhibitor, with the corresponding $\mathrm{E}_{\mathrm{L}}$ (more negative values correspond to greater net electron donation to the metal center from the ligand) ${ }^{44}$ and resonance parameters (more negative values indicate greater ligand $\pi$-donor character). ${ }^{45}$ Best fit parameters were obtained using eq. 1 and 2 with $K_{\mathrm{M}}^{\text {formate }}=0.8 \mathrm{mM}, K_{\mathrm{M}}{ }^{\mathrm{CO} 2}=2.5 \mathrm{mM}, E_{1}=-0.365 \mathrm{~V}$ vs. SHE, $E_{2}=-0.656 \mathrm{~V}$ vs. SHE, $k_{\text {cat }}^{\text {formate }} / k_{0}=0.5, k_{\text {cat }}{ }^{\mathrm{CO} 2} / k_{0}=5.13$ and are taken from Figure S4. 


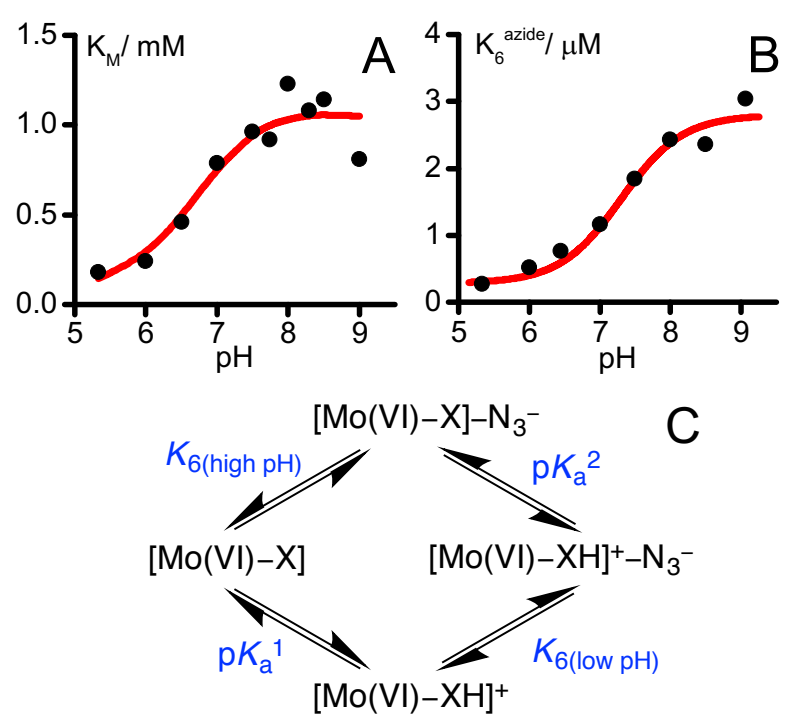

Figure 5. The $\mathrm{pH}$ dependence of $K_{\mathrm{M}}{ }^{\text {formate }}$ and $K_{6}{ }^{\text {azide }}$. Data for each $\mathrm{pH}$ were measured at $0.4 \mathrm{~V}$ above the Nernst potential of the $\mathrm{CO}_{2} /$ formate couple at $23.5^{\circ} \mathrm{C}$. A) Dependence of $K_{\mathrm{M}}{ }^{\text {formate }}$ on pH. B) Dependence of $K_{6}$ azide on $\mathrm{pH}$. C) Scheme showing how the protonation of a nearby base $(\mathrm{X})$ influences inhibitor and proton binding. The scheme in $\mathrm{C}$ was used to fit the data in $\mathrm{B}$, with $K_{6(\text { high pH) }}=2.82 \mu \mathrm{M}, \mathrm{p} K_{\mathrm{a}}{ }^{1}=6.3$ (for the inhibitorfree state), $\mathrm{p} K_{\mathrm{a}}{ }^{2}=7.3$ (for the inhibitor-bound state) and thus $K_{6(\text { low } \mathrm{pH})}=0.36 \mu \mathrm{M}$. The curve in $\mathrm{A}$ is

only to guide the eye because the closed thermodynamic scheme in $\mathrm{C}$ does not apply under turnover conditions.

\section{DISCUSSION}

A crucial feature of PFE is that experiments are conducted at precisely-controlled potentials. Therefore, in contrast to standard solution kinetics experiments, PFE allows the potential and time domains to be distinguished, providing new perspectives on redox-coupled reactions. Here, we undertook a detailed electrochemical investigation of how Mo-containing $E c \mathrm{FDH}-\mathrm{H}$ is inhibited by $\mathrm{N}_{3}{ }^{-}$and showed that both the strong inhibition of formate oxidation and the weaker inhibition of $\mathrm{CO}_{2}$ reduction result from selective binding of $\mathrm{N}_{3}^{-}$to the $\mathrm{Mo}(\mathrm{VI})$ state. Our model explains why $\mathrm{N}_{3}{ }^{-}$inhibition of formate oxidation is competitive (both formate and $\mathrm{N}_{3}^{-}$bind to the $\mathrm{Mo}(\mathrm{VI})$ state), but inhibition of $\mathrm{CO}_{2}$ reduction is not $\left(\mathrm{CO}_{2}\right.$ reacts with the $\mathrm{Mo}(\mathrm{IV})$ state). It explains why the $\mathrm{IC}_{50}$ values observed for $\mathrm{CO}_{2}$ are potential dependent (Mo(VI) is present at higher steady-state levels at more positive potentials) and how the unusual trend of increased inhibition with increased $\mathrm{CO}_{2}$ concentration arises (from increasing enzyme catalysis increasing the steady-state level of Mo(VI)). The same selectivity for the Mo(VI) state was observed for several other inhibitors tested $\left(\mathrm{OCN}^{-}, \mathrm{SCN}^{-}\right.$and $\left.\mathrm{NO}_{3}{ }^{-}\right)$, with only $\mathrm{NO}_{2}^{-}$displaying a different pattern of selectivity $\left(K_{4}<K_{5}<K_{6}\right)$, perhaps because its bent structure renders it a transition state analog. 
The strong selectivity of the inhibitors for specific oxidation states of the Mo center place the inhibitor binding site firmly within its vicinity, and the competitive inhibition of formate oxidation suggests the formate and inhibitor binding sites overlap temporally and spatially. Together, these observations exclude inhibitor binding in a redox-independent region of the enzyme, such as in a distant substrate-access channel. The simplest model for the marked oxidation state selectivity, consistent with all proposed mechanisms of catalysis, is that substrates/inhibitors bind directly to the Mo center itself, either to a vacant coordination site on the $\mathrm{Mo}$, or to the $\mathrm{Mo}(\mathrm{VI})=\mathrm{S}$ group. In addition, changes in active site hydrophobicity have been proposed to aid formate oxidation in metal-independent formate dehydrogenase enzymes ${ }^{46}$ (since formate is charged and hydrophilic and $\mathrm{CO}_{2}$ is neutral and relatively hydrophobic) and may also contribute. Redox-driven dissociation of the Sec ligand (discussed above) or reduction of the pyranopterin cofactors to their 'tetrahydro' form ${ }^{30}$ could also induce conformational changes and create or destroy substrate/inhibitor binding sites. However, we consider these secondary explanations much less likely than direct interactions with the Mo center itself.

Simple charge density considerations suggest that direct Mo-binding inhibitors are likely to bind more tightly to $\mathrm{Mo}(\mathrm{VI})$ than $\mathrm{Mo}(\mathrm{IV})$. Furthermore, Figure 6 shows that the inhibitor $K_{6}$ values correlate with both the ligand electrochemical parameter $\left(E_{\mathrm{L}}\right.$, which becomes more negative with increasing net ligand electron donation) ${ }^{44}$ and with the ligand resonance field donation ${ }^{45}$ (which decreases with increasing ligand $\pi$-electron donating ability). Thus, the properties of both the Mo center and the inhibitor govern their affinity for one another, consistent with direct bonding between them. Tighter binding inhibitors are better net electron donors and better $\pi$-electron donors than more weakly binding inhibitors, indicating that the inhibitor binding site on the Mo(VI) center is an electron acceptor site. This characteristic is more consistent with the electron deficient Mo than the electron rich sulfide. Furthermore, the indication that inhibitor binding to Mo(VI) is also affected by $\pi$-donation into empty Mo $4 \mathrm{~d}$ orbitals suggests $\mathrm{Mo}(\mathrm{VI})$ may engage in $\pi$-interactions during catalysis. These observations all support direct substrate/inhibitor binding directly to a vacant coordination site on the Mo itself, rather than to the sulfide. Although this conclusion is challenged by reports that $\mathrm{N}_{3}^{-}, \mathrm{OCN}^{-}, \mathrm{SCN}^{-}, \mathrm{NO}_{2}^{-}$and $\mathrm{NO}_{3}{ }^{-}$also competitively inhibit formate oxidation in metal-independent FDHs (such as yeast formate dehydrogenase, which catalyze direct hydride transfer from formate to $\left.\mathrm{NAD}(\mathrm{P})^{+}\right)^{46,47}$ it is not suprising that two enzymes that oxidize the same substrate exhibit similar active site specificities. In metalindependent FDHs, structural data has shown that His and Arg residues in the active site stabilize bound $\mathrm{N}_{3}{ }^{-}$by hydrogen bonding, ${ }^{46}$ and Arg and His residues are also present in the active site of EcFDH-H. 
The $\mathrm{p} K_{\mathrm{a}}$ values observed for $\mathrm{N}_{3}{ }^{-}$binding in $E c \mathrm{FDH}-\mathrm{H}$ (see Figure 5) are consistent with a His residue stabilizing the inhibitor/substrate most effectively in its protonated state.

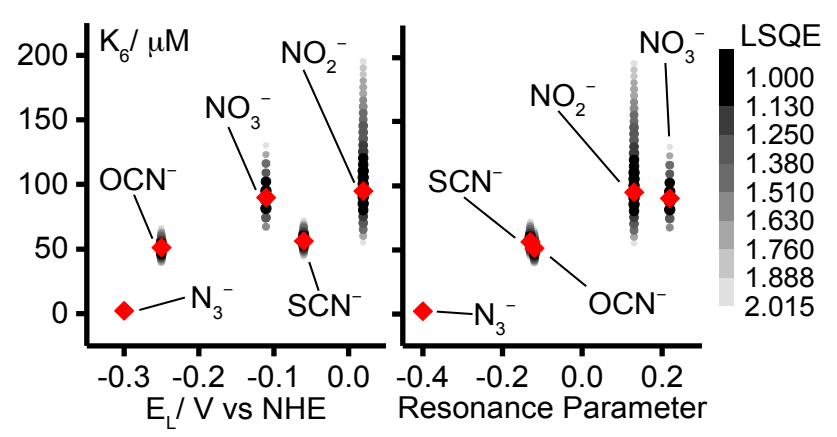

Figure 6. Dependence of $K_{6}$ on ligand electrochemical $\left(E_{\mathrm{L}}\right)^{44}$ and resonance parameters. ${ }^{45}$ Red diamonds: best fit values, dots: values within the acceptable error threshold (see Figures S2 and S5), shaded according to the normalized LSQE.

The Sec residue would have to dissociate to generate a vacant coordination site for substrates/inhibitors to bind directly to the Mo. As described above, structural and spectroscopic data on the Mo coordination in the Mo(IV) state are inconclusive. However, it is only necessary for the Sec to dissociate transiently for substrates/inhibitors to bind to its coordination site. Support for a competitive binding model is provided by inactivation of Mo-containing FDHs by iodoacetamide (that reacts with nucleophilic Sec (or Cys) residues) in the presence of formate ${ }^{48}$ or $\mathrm{NO}_{3}{ }^{-}$(the iodoacetamide has been confirmed to derivatize the active site Cys residue in $R$. capsulatus FDH). ${ }^{39}$ The Sec may thus exist in a distribution of bound and free states that favors the bound state more strongly for the high-charge density Mo(VI) than for Mo(IV), and it may be crucial for FDH catalysis simply because it stabilizes the resting enzyme. Previously, a 'sulfur-selenium shift' mechanism was proposed for Sec dissociation, in which the approach of formate triggers insertion of the sulfido ligand into the Se-Mo bond, ${ }^{34,35}$ but there is little experimental support for S-Se bond formation. Finally, reductive activation of FDH catalysis, independent of formate, has been noted for D. sulfuricans $\mathrm{FDH}^{3}$ and was also observed for $\mathrm{CO}_{2}$ reduction (by reduced methyl viologen) in the W-containing FDH from S. fumaroxidans. ${ }^{1}$ A similar phenomenon was observed here in electrocatalytic experiments on $E c F D H-H$ in the presence of $\mathrm{CO}_{2}$ and formate (see Figure 7). When the potential is swept cathodically from $-0.2 \mathrm{~V}$ to $-0.6 \mathrm{~V}$, catalysis is not observed until the onset of $\mathrm{CO}_{2}$ reduction, despite the driving force being sufficient for formate oxidation. When the potential returns, formate oxidation is observed where previously there was none, and subequent scans show formate oxidation currents in both scan directions. The reductive activation 
may represent formation of a stabilized Sec-dissociated state when the steady-state level of the Mo(IV) state increases.

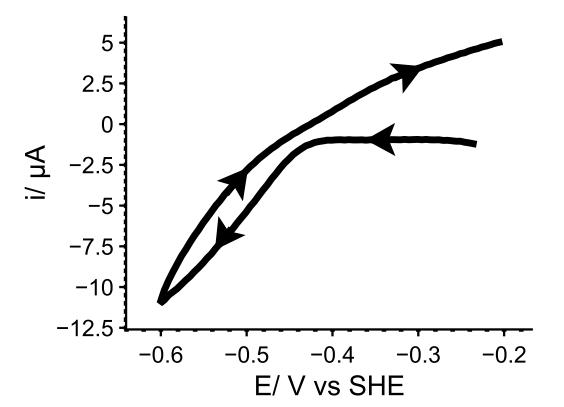

Figure 7. Reductive activation of electrocatalysis by $E c \mathrm{FDH}-\mathrm{H}$. Arrows indicate the voltammetric scan direction. $\mathrm{pH} 7.2,10 \mathrm{mM} \mathrm{CO}_{2}$, $10 \mathrm{mM}$ formate, $25 \mathrm{mM}$ each MES, TAPS, HEPES, $\mathrm{K}^{+}$acetate, 23.5 ${ }^{\circ} \mathrm{C}, 2000 \mathrm{rpm}$, scan rate $25 \mathrm{mVs}^{-1}$.

Figure 8 shows the key intermediates formed in three proposed mechanisms for FDH catalysis. In the mechanism shown in Figure 8A, formate donates a hydride to the sulfido group of the $\mathrm{Mo}(\mathrm{VI})=\mathrm{S}$ center. ${ }^{32}$ However, it is unclear if the $\mathrm{S}$ center is a sufficiently strong hydride acceptor. In model complexes, formation of Mo-SH groups appears dominated by protonation reactions, ${ }^{49-51}$ and although $\left[\mathrm{Cp}^{*}{ }_{2} \mathrm{Mo}_{2} \mathrm{~S}_{4}\right]$-type complexes containing bridging sulfides have been tuned to be thermodynamicallycapable hydride donors or acceptors, ${ }^{52}$ their kinetic behavior has not been investigated. The mechanism in Figure 8A is consistent with the mechanism of catalysis by metal-independent FDHs, ${ }^{46}$ which demonstrate the possibility of a Mo-independent hydride transfer reaction. However, $\mathrm{NAD}^{+}$is an obligatory hydride acceptor, whereas the FDH-Mo center has a stable one-electron intermediate state, $\mathrm{Mo}(\mathrm{V})$, and far more versatile chemistry. In addition, $\mathrm{CN}^{-}$-driven removal of the sulfido ligand as $\mathrm{SCN}^{-}$ ${ }^{22,53}$ may occur by nucleophilic attack by $\mathrm{CN}^{-}$on the sulfido group, in analogy with the hydride attack shown in Figure 8A, but the reaction mechanism is unknown and may be initiated by $\mathrm{CN}^{-}$attack on the Mo instead. Central to the proposal in Figure 8A is the relationship between FDH and the enzyme xanthine oxidase $(\mathrm{XO})$, in which the sulfido group of the $\mathrm{Mo}(\mathrm{VI})=\mathrm{S}$ center has been discussed as a hydride acceptor. ${ }^{24}$ However, classification of the $\mathrm{XO}$ reaction as a direct hydride transfer reaction that can simply be represented by the movement of electron pairs is an oversimplification of the complex molecular orbital interactions that occur during formation of the transition state, which have been elucidated by density functional theory (DFT) calculations. ${ }^{54,55}$ Furthermore, FDH and XO have different Mo coordination and geometry. The sulfido group in $\mathrm{XO}$ is in an equatorial position and able to access a low-lying $d_{x y} \pi^{*}$ LUMO whereas the electronic structure of the Mo centre in FDH is clearly different (but currently not well defined). More importantly, for Mo-FDH to catalyse $\mathrm{CO}_{2}$ reduction effectively, the mechanism in Figure 8A would require Mo(IV)-SH to be an excellent hydride donor, 
capable of rapid and efficient hydride attack on the carbon atom in $\mathrm{CO}_{2}$. Future work to evaluate and compare the hydricity and acidity of the $\mathrm{Mo}(\mathrm{VI})=\mathrm{SH}$ group may thus prove crucial in deciding whether Figure $8 \mathrm{~A}$ is relevant to the mechanism of FDH catalysis.

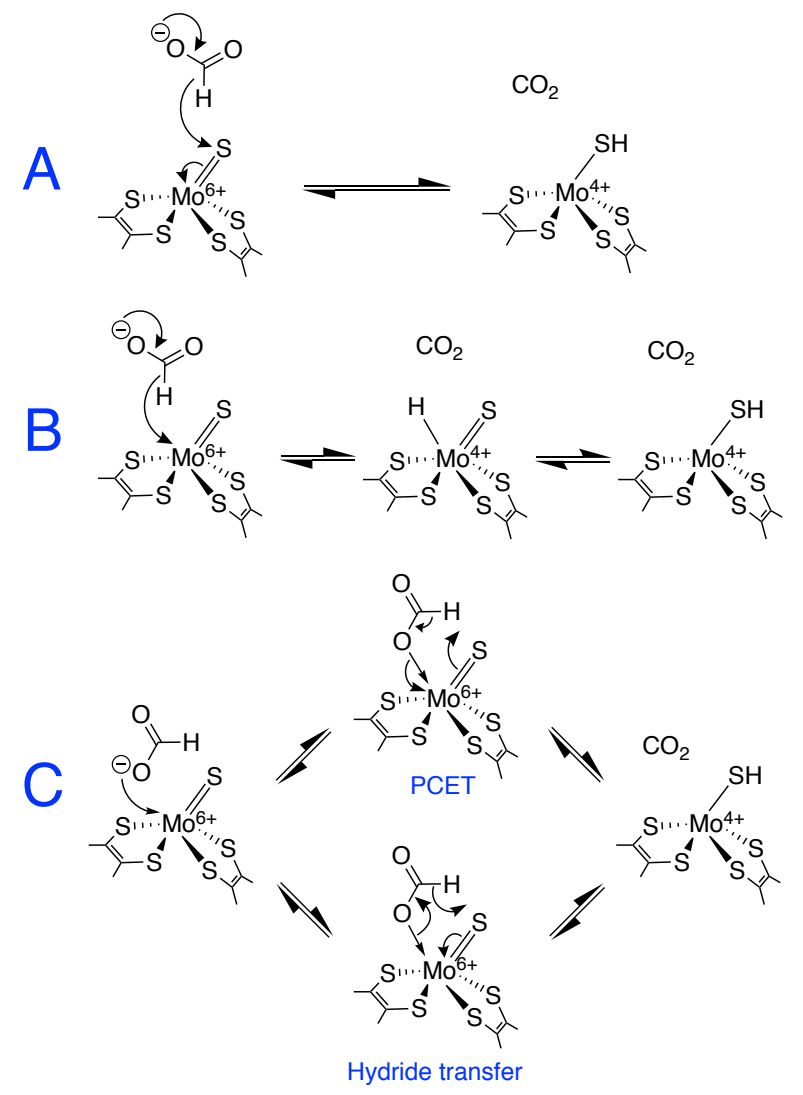

Figure 8: Possible mechanisms of formate oxidation by $E c \mathrm{FDH}-\mathrm{H}$ that generate the $\mathrm{Mo}(\mathrm{IV})-\mathrm{SH}$ product. A) Hydride transfer mechanism of Hille and coworkers. ${ }^{32}$ B) Direct hydride transfer to the Mo, followed by hydride migration to the sulfur, proposed by Zampella and coworkers. ${ }^{33} \mathrm{C}$ ) Two alternative representations of the 5-membered transition state mechanism proposed here.

The mechanisms shown in Figures $8 \mathrm{~B}$ and $8 \mathrm{C}$ require $\mathrm{Sec}$ dissociation to occur. The metal hydride formed in Figure $8 \mathrm{~B}^{33}$ is attractive for $\mathrm{CO}_{2}$ activation; it represents a motif present in organometallic compounds that activate formate and $\mathrm{CO}_{2}$ (for example, the cyclopentadienyl Mo- $\mathrm{H}$ compounds that catalyze formate dehydrogenation ${ }^{56}$ ) and is consistent with formation of the $\mathrm{Mo}(\mathrm{V})-\mathrm{SH}$ species because the hydride could migrate to the sulfido group upon oxidation of the Mo(IV) to Mo(V) (to then be lost completely upon its oxidation to Mo(IV)). This mechanism has been investigated extensively using DFT calculations on organometallic complexes, which have further suggested formation of the metal-formato complex following hydride insertion. ${ }^{57,58}$ However, the mechanism is more characteristic of electron-rich metal centers such as $\mathrm{Ru}(\mathrm{II})$ than of $\mathrm{Mo}(\mathrm{IV})$, and known $\mathrm{Mo}(\mathrm{IV})-\mathrm{H}$ compounds are also unstable in the presence of $\mathrm{H}^{+}$since they readily evolve $\mathrm{H}_{2}{ }^{59}$ Furthermore, direct hydride transfer to Mo does not take advantage of donor-acceptor interactions between the Mo=S and 
the $\mathrm{C}-\mathrm{H}$ of the formate to weaken the $\mathrm{C}-\mathrm{H}$ bond, as are understood to be crucial for transition state stabilization during catalysis by XO.

In Figure $8 \mathrm{C}$ we propose that formate coordinates to the Mo via its oxygen lone pairs, and that formate oxidation occurs by via a 5-membered transition state that results directly in the Mo(IV)-SH product, and that resembles the transition state formed in $\mathrm{XO}$. The reaction is drawn in Figure $8 \mathrm{C}$ either as a proton-coupled electron-transfer (PCET) reaction, or as a hydride transfer reaction, simply by moving the arrows in opposite directions around the 5-membered ring. In fact, the simple arrow representation cannot accurately reflect the complexity of the molecular orbital transitions that are probably involved. It is likely that (in analogy with $\mathrm{XO}$ ) the reaction proceeds by intramolecular electron transfer within a transition state formed by interactions of $\mathrm{Mo}=\mathrm{S} \pi$ and $\pi^{*}$ orbitals with $\mathrm{C}-\mathrm{H} \sigma$ and $\sigma^{*}$ orbitals. ${ }^{54}$ The mechanism in Figure $8 \mathrm{C}$ avoids the formation of potentially $\mathrm{H}_{2}$-evolving Mo- $\mathrm{H}$ species $^{59}$ and, in PCET form, is similar to that proposed by Kubiak and coworkers for a Ni-based inorganic catalyst. ${ }^{16,17}$ For $\mathrm{CO}_{2}$ reduction, the mechanism shown in Figure $8 \mathrm{C}$ suggests that $\mathrm{CO}_{2}$ itself does not strongly interact with the Mo, but that the Mo-O bond is formed as the reaction crosses the transition state, resulting in the coordinated formate product. In a related manner, DFT calculations have suggested that, for reduction to formate, $\mathrm{CO}_{2}$ binds end-on to the $\mathrm{Ni}(\mathrm{I})$ in $\mathrm{Ni}$ cyclam complexes, in a bent conformation in which the C-O bonds become elongated and poised for the subsequent reaction. ${ }^{60}$

Finally, we compare the mechanism of Mo-containing FDH with the mechanisms of two other enzymes that activate $\mathrm{CO}_{2}$. Carbonic anhydrase converts $\mathrm{CO}_{2}$ to $\mathrm{HCO}_{3}{ }^{-}$through attack of a $\mathrm{Zn}$-activated nucleophilic $\mathrm{OH}^{-}$on the central $\mathrm{C}$ atom. ${ }^{61}$ Although donation of hydride by the $\mathrm{Mo}^{\mathrm{IV}}-\mathrm{SH}$ in FDH resembles this mechanism, we note that the hydride has no nucleophilic lone pair and the equivalent step would require concerted cleavage of the $\mathrm{SH}$ bond, as shown in Figure 8C. $\mathrm{CO}$ dehydrogenase reduces $\mathrm{CO}_{2}$ to $\mathrm{CO}$ using an unusual $\mathrm{NiFe}_{4} \mathrm{~S}_{4}$ cluster. Detailed structural and functional data support a mechanism in which the electron-rich $\mathrm{Ni}$ centre attacks on the central $\mathrm{C}$ atom of $\mathrm{CO}_{2}$, and the resulting intermediate is stabilized by co-ordination of one of the $\mathrm{O}$ atoms of the $\mathrm{CO}_{2}$ to a cluster Fe centre; the intermediate then proceeds to a Ni-CO species through protonation and loss of the Fe-coordinated $\mathrm{O}$ atom. ${ }^{62,63}$ The hydride-based mechanism shown in Figure $8 \mathrm{C}$ is analogous to this mechanism, with hydride attacking in place of $\mathrm{Ni}$, and $\mathrm{Mo}-\mathrm{O}$ bond formation in place of Fe-O bond formation. The comparison supports the importance of Mo-O bond formation as a driving force for $\mathrm{CO}_{2}$ reduction by FDH, with the reaction then completed simply by dissociation of the nascent formate.

\section{CONCLUSIONS}


We have shown that inhibition of FDH catalysis is strongly dependent on the oxidation state of the enzyme, suggesting that inhibitors and substrates interact intimately with the Mo center in the active site. Based on the data presented we propose a mechanism in which an open coordination site is formed on the Mo by reversible dissociation of the Sec ligand. The Sec may bind to stabilize the Mo center in the resting enzyme. We propose that $\mathrm{CO}_{2}$ /formate interconversion proceeds via a 5-membered transition state involving the sulfido ligand. To further test the mechanistic proposals discussed here will require electrochemical, spectroscopic, computational and structural data to be combined to probe the kinetics and thermodynamics of both $\mathrm{CO}_{2}$ reduction and formate oxidation, and to define the structures of the intermediates formed.

\section{Associated Content}

Supporting Information: Figures S1-S4, the data analysis code, and the derivation of equation 1. This material is available free of charge via the Internet at http://pubs.acs.org.

\section{Corresponding Authors}

reisner@ch.cam.ac.uk; jh@mrc-mbu.cam.ac.uk

\section{Acknowledgements}

This research was supported by BBSRC (BB/I026367/1 and BB/J000124/1), EPSRC NanoDTC Cambridge (EP/L015978/1), an ERC Consolidator Grant 'MatEnSAP' (682833), and by The Medical Research Council (U105663141).

\section{References}

(1) Reda, T.; Plugge, C. M.; Abram, N. J.; Hirst, J. Proc. Natl. Acad. Sci. U. S. A. 2008, 105, 1065410658.

(2) Bassegoda, A.; Madden, C.; Wakerley, D. W.; Reisner, E.; Hirst, J. J. Am. Chem. Soc. 2014, 136, $15473-15476$.

(3) Maia, L. B.; Fonseca, L.; Moura, I.; Moura, J. J. G. J. Am. Chem. Soc. 2016, 138, 8834-8846.

(4) Hartmann, T.; Leimkühler, S. FEBS J. 2013, 280, 6083-6096.

(5) Wagner, T.; Ermler, U.; Shima, S. Science 2016, 354, 114-117.

(6) Kang, P.; Cheng, C.; Chen, Z.; Schauer, C. K.; Meyer, T. J.; Brookhart, M. J. Am. Chem. Soc. 2012, 134, 5500-5503.

(7) Kang, P.; Meyer, T. J.; Brookhart, M. Chem. Sci. 2013, 4, 3497-3502.

(8) Kang, P.; Zhang, S.; Meyer, T. J.; Brookhart, M. Angew. Chemie Int. Ed. 2014, 53, 8709-8713. 
(9) Machan, C. W.; Sampson, M. D.; Kubiak, C. P. J. Am. Chem. Soc. 2015, 137, 8564-8571.

(10) Collin, J. P.; Jouaiti, A.; Sauvage, J. P. Inorg. Chem. 1988, 27, 1986-1990.

(11) Chen, L.; Guo, Z.; Wei, X.-G.; Gallenkamp, C.; Bonin, J.; Anxolabéhère-Mallart, E.; Lau, K.-C.; Lau, T.-C.; Robert, M. J. Am. Chem. Soc. 2015, 137, 10918-10921.

(12) Pun, S.-N.; Chung, W.-H.; Lam, K.-M.; Guo, P.; Chan, P.-H.; Wong, K.-Y.; Che, C.-M.; Chen, T.-Y.; Peng, S.-M. J. Chem. Soc. Dalt. Trans. 2002, No. 4, 575-583.

(13) Franco, F.; Cometto, C.; Ferrero Vallana, F.; Sordello, F.; Priola, E.; Minero, C.; Nervi, C.; Gobetto, R. Chem. Commun. 2014, 50, 14670-14673.

(14) Taheri, A.; Thompson, E. J.; Fettinger, J. C.; Berben, L. A. ACS Catal. 2015, 5, 7140-7151.

(15) Roy, S.; Sharma, B.; Pécaut, J.; Simon, P.; Fontecave, M.; Tran, P. D.; Derat, E.; Artero, V. J. Am. Chem. Soc. 2017, 139, 3685-3696.

(16) Galan, B. R.; Schöffel, J.; Linehan, J. C.; Seu, C.; Appel, A. M.; Roberts, J. A. S.; Helm, M. L.; Kilgore, U. J.; Yang, J. Y.; DuBois, D. L.; Kubiak, C. P. J. Am. Chem. Soc. 2011, 133, 1276712779.

(17) Seu, C. S.; Appel, A. M.; Doud, M. D.; DuBois, D. L.; Kubiak, C. P. Energy Environ. Sci. 2012, $5,6480-6490$.

(18) Armstrong, F. A.; Hirst, J. Proc. Natl. Acad. Sci. U. S. A. 2011, 108, 14049-14054.

(19) Boyington, J. C.; Gladyshev, V. N.; Khangulov, S. V.; Stadtman, T. C.; Sun, P. D. Science 1997, 275, 1305-1308.

(20) Raaijmakers, H.; Macieira, S.; Dias, J. M.; Teixeira, S.; Bursakov, S.; Huber, R.; Moura, J. J. G.; Moura, I.; Romão, M. J. Structure 2002, 10, 1261-1272.

(21) Jormakka, M.; Törnroth, J.; Byrne, B.; Iwata, S. Science 2002, 295, 1863-1868.

(22) Thomé, R.; Gust, A.; Toci, R.; Mendel, R.; Bittner, F.; Magalon, A.; Walburger, A. J. Biol. Chem. 2012, 287, 4671-4678.

(23) Schrapers, P.; Hartmann, T.; Kositzki, R.; Dau, H.; Reschke, S.; Schulzke, C.; Leimkühler, S.; Haumann, M. Inorg. Chem. 2015, 54, 3260-3271.

(24) Hille, R.; Hall, J.; Basu, P. Chem. Rev. 2014, 114, 3963-4038.

(25) Adamson, H.; Simonov, A. N.; Kierzek, M.; Rothery, R. A.; Weiner, J. H.; Bond, A. M.; Parkin, A. Proc. Natl. Acad. Sci. U. S. A. 2015, 112, 14506-14511.

(26) Raaijmakers, H. C.; Romão, M. J. J. Biol. Inorg. Chem. 2006, 11, 849-854.

(27) George, G. N.; Colangelo, C. M.; Dong, J.; Scott, R. A.; Khangulov, S. V.; Gladyshev, V. N.; Stadtman, T. C. J. Am. Chem. Soc. 1998, 120, 1267-1273. 
(28) George, G. N.; Costa, C.; Moura, J. G.; Moura, I. J. Am. Chem. Soc. 1999, 121, 2625-2626.

(29) Khangulov, S. V.; Gladyshev, V. N.; Dismukes, G. C.; Stadtman, T. C. Biochemistry 1998, 37, $3518-3528$.

(30) Gladyshev, V. N.; Khangulov, S. V; Axley, M. J.; Stadtman, T. C. Proc. Natl. Acad. Sci. U. S. A. 1994, 91, 7708-7711.

(31) Rivas, M. G.; González, P. J.; Brondino, C. D.; Moura, J. J. G.; Moura, I. J. Inorg. Biochem. 2007, 101, 1617-1622.

(32) Niks, D.; Duvvuru, J.; Escalona, M.; Hille, R. J. Biol. Chem. 2016, 291, 1162-1174.

(33) Tiberti, M.; Papaleo, E.; Russo, N.; De Gioia, L.; Zampella, G. Inorg. Chem. 2012, 51, 83318339.

(34) Mota, C. S.; Rivas, M. G.; Brondino, C. D.; Moura, I.; Moura, J. J. G.; González, P. J.; Cerqueira, N. M. F. S. A. J. Biol. Inorg. Chem. 2011, 16, 1255-1268.

(35) Cerqueira, N. M. F. S. A.; Fernandes, P.; Gonzalez, P. J.; Moura, J. J. G.; Ramos, M. J. Inorg. Chem. 2013, 52, 10766-10772.

(36) Fourmond, V.; Lautier, T.; Baffert, C.; Leroux, F.; Liebgott, P.-P.; Dementin, S.; Rousset, M.; Arnoux, P.; Pignol, D.; Meynial-Salles, I.; Soucaille, P.; Bertrand, P.; Léger, C. Anal. Chem. 2009, 81, 2962-2968.

(37) Dixon, M. Biochem. J. 1953, 55, 170-171.

(38) Axley, M. J.; Grahame, D. A. J. Biol. Chem. 1991, 266, 13731-13736.

(39) Hartmann, T.; Schrapers, P.; Utesch, T.; Nimtz, M.; Rippers, Y.; Dau, H.; Mroginski, M. A.; Haumann, M.; Leimkühler, S. Biochemistry 2016, 55, 2381-2389.

(40) Axley, M. J.; Grahame, D. A.; Stadtman, T. C. J. Biol. Chem. 1990, 265, 18213-18218.

(41) Léger, C.; Bertrand, P. Chem. Rev. 2008, 108, 2379-2438.

(42) Cheng, Y.-C.; Prusoff, W. H. Biochem. Pharmacol. 1973, 22, 3099-3108.

(43) Léger, C.; Lederer, F.; Guigliarelli, B.; Bertrand, P. J. Am. Chem. Soc. 2006, 128, 180-187.

(44) Lever, A. B. P. Inorg. Chem. 1990, 29, 1271-1285.

(45) Hansch, C.; Leo, A.; Taft, R. W. Chem. Rev. 1991, 91, 165-195.

(46) Popov, V.; Lamzin, V. Biochem. J. 1994, 301, 625-643.

(47) Blanchard, J. S.; Cleland, W. W. Biochemistry 1980, 19, 3543-3550.

(48) Axley, M. J.; Bock, A.; Stadtman, T. C. Proc. Natl. Acad. Sci. U. S. A. 1991, 88, 8450-8454.

(49) Smith, P. D.; Slizys, D. A.; George, G. N.; Young, C. G. J. Am. Chem. Soc. 2000, 122, 29462947. 
(50) Smith, S. J.; Whaley, C. M.; Rauchfuss, T. B.; Wilson, S. R. Inorg. Chem. 2006, 45, 679-687.

(51) Birnbaum, J.; Godziela, G.; Maciejewski, M.; Tonker, T. L.; Haltiwanger, R. C.; Rakowski DuBois, M. Organometallics 1990, 9, 394-401.

(52) Appel, A. M.; Lee, S.; Franz, J. A.; DuBois, D. L.; Rakowski DuBois, M. J. Am. Chem. Soc. 2009, 131, 5224-5232.

(53) Barber, M. J.; May, H. D.; Ferry, J. G. Biochemistry 1986, 25, 8150-8155.

(54) Sempombe, J.; Stein, B.; Kirk, M. L. Inorg. Chem. 2011, 50, 10919-10928.

(55) Doonan, C. J.; Rubie, N. D.; Peariso, K.; Harris, H. H.; Knottenbelt, S. Z.; George, G. N.; Young, C. G.; Kirk, M. L. J. Am. Chem. Soc. 2008, 130, 55-65.

(56) Neary, M. C.; Parkin, G. Chem. Sci. 2015, 6, 1859-1865.

(57) Kumar, N.; Camaioni, D. M.; Dupuis, M.; Raugei, S.; Appel, A. M. Dalt. Trans. 2014, 43, 11803.

(58) Xue, L.; Ahlquist, M. S. G. Inorg. Chem. 2014, 53, 3281-3289.

(59) Porcher, J.-P.; Fogeron, T.; Gomez-Mingot, M.; Derat, E.; Chamoreau, L.-M.; Li, Y.; Fontecave, M. Angew. Chem. Int. Ed. 2015, 54, 14090-14093.

(60) Song, J.; Klein, E. L.; Neese, F.; Ye, S. Inorg. Chem. 2014, 53, 7500-7507.

(61) Lindskog, S. Pharmacol. Ther. 1997, 74, 1-20.

(62) Can, M.; Armstrong, F. A.; Ragsdale, S. W. Chem. Rev. 2014, 114, 4149-4174.

(63) Fesseler, J.; Jeoung, J. H.; Dobbek, H. Angew. Chemie Int. Ed. 2015, 54, 8560-8564.

\section{Table of Contents Graphic}

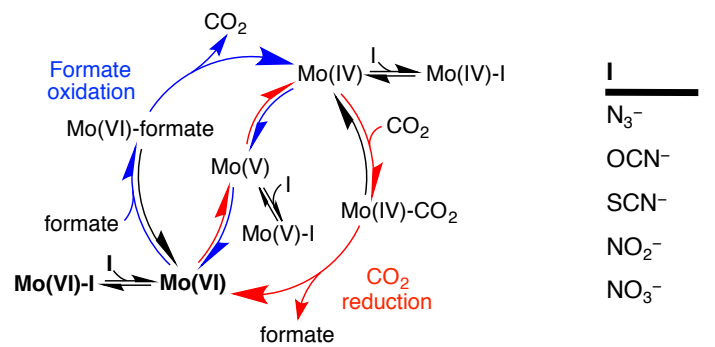

